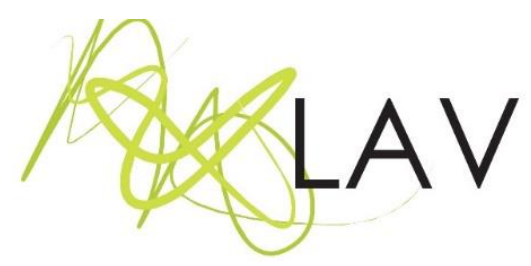

\title{
Cartografias de uma experiência em Artes Visuais ${ }^{1}$
}

Cartographies of experience in Visual Arts

Fabio Wosniak

Universidade do Estado de Santa Catarina

\section{Resumo}

Esse texto aborda os vínculos entre experiência, Artes Visuais e Educação, através de uma articulação de ensino e aprendizagem de arte criada no Grupo de Estudos Estúdio de Pintura Apotheke, ancorado na Filosofia da Arte como experiência de John Dewey (1859-1952).

Palavras-chave: Arte como experiência, ensino/aprendizagem em Artes Visuais, Arte/Educação.

\section{Abstract}

This paper addresses the connection between experience, Visual Arts and Education, through an articulation between the teaching and learning of Art, created in the Study Group Apotheke Painting Studio anchored in the Philosophy of Art as experience by John Dewey (1859-1952).

Keywords: Art as experience, Visual Arts education/learning, Art/Education.

A obra de arte provoca e acentua essa característica de ser um todo e de pertencer ao todo maior e abrangente que é o universo em que vivemos. Essa é, a meu ver, a explicação da sensação de requintada inteligibilidade e clareza que temos na presença de um objeto vivenciado com intensidade estética.

Fragmento do livro Arte como experiência de John Dewey

Arte como Experiência foi o último livro escrito por John Dewey, publicado nos Estados Unidos em 1934. Sua publicação no Brasil ocorreu no ano de 2010 pela Editora Martins Fontes. É uma obra, como comenta o autor no prefácio, que nasce no inverno e segue até a primavera do ano de 1931. Os escritos do livro foram resultado de conferências que o filósofo proferiu na Universidade de Harvard sobre o

${ }^{1}$ Este texto é um extrato da Dissertação de Mestrado defendida no PPGAV/UDESC em 2015.

Revista Digital do LAV - Santa Maria - vol. 11, n. 1, p. 103 - 120 - jan./abr. 2018 ISSN 1983 - 7348 http://dx.doi.org/10.5902/1983734827867 
tema Filosofia da Arte.

É exclusivamente essa obra de Dewey a escolhida para encontrar caminhos que revelem uma nova perspectiva sobre o tema abordado neste artigo. Mas antes, vale lembrar que Dewey foi precursor inspirador das reformas de um ensino centrado na criança. Assim, o autor não apenas refletiu sobre uma Filosofia da Arte pautada na experiência, mas pensou também em uma Educação que necessitava rever seu conjunto teórico - o autor adverte para uma Educação que tenha como base uma teoria da experiência.

Alinhado a esse pensamento teórico de Dewey sobre Arte, Educação e Experiência, teço travessias de um pensamento cartográfico para descrever uma experiência sobre ensinar e aprender Artes Visuais. Assim sendo, o objetivo deste estudo é interpretar e compreender a articulação entre o fazer-pensar estético-artístico e sua relevância para a Educação.

\section{Travessia 1: por uma educação em Artes Visuais pautada na experiência}

Tomando em sua mão algumas sobras do mundo, o homem pode inventar um novo mundo que é todo dele. A arte começa pela transmutação e continua pela metamorfose.

Focillon

A proposta de John Dewey (1859-1952) é elaborar uma teoria da experiência na Educação, ou seja, uma Filosofia da Experiência. Nela, o autor norte-americano considera relevante considerar os fatores sociais, culturais e individuais. John Dewey é filósofo, foi responsável pela teoria da Escola Nova. Suas ideias estão amplamente divulgadas em seus livros. Dentre eles, destaco Arte como Experiência, na sua primeira edição publicada em português pela Editora Martins Fontes em 2010, e Experiência e Educação, editado pela segunda vez com o selo da Editora Vozes, em 2011. Esses são os dois livros que mais interessam a este estudo. Outros títulos do autor incluem Democracia e Educação, de 1916, e Como Pensamos, de 1910.

Dewey, em seus escritos, destaca os problemas da sociedade industrial moderna, assim como as instâncias do humano diante dos progressos frente ao modelo social e econômico capitalista. Para o filósofo, a educação tal como se apresenta, em seu formato tradicional, não faz outra coisa senão "transmitir" conhecimentos às novas 
gerações - esses, formulados de forma genérica, transformados em um conjunto de informações e de habilidades elaborados no passado (DEWEY, 2011).

Nesta perspectiva, a concepção de aprendizagem, apresentada no modelo tradicional, é aquela em que os estudantes apenas "consomem" os conhecimentos das gerações anteriores, sem nenhuma ação crítico-reflexiva. Essa constitui uma das principais críticas à educação encontradas nos escritos de John Dewey. A partir da observação cuidadosa da sociedade de sua época, Dewey passa a defender uma educação pela experiência.

O conceito de experiência é central no pensamento deweiano. O autor explica que "experiência e educação não são diretamente equivalentes uma a outra" (DEWEY, 2011, p. 27). E continua:

[...] dentre todas as incertezas, existe um quadro de referência permanente: de que há uma conexão orgânica entre educação e experiência pessoal, ou seja, de que a nova Filosofia da Educação está comprometida com algum tipo de filosofia empírica e experimental. Porém, experiência e experimento não são ideias autoexplicativas. Ao contrário, seus significados são parte de um problema a ser explorado. Para saber 0 significado de empirismo, precisamos compreender o que é experiência (DEWEY, 2011, p. 26).

É isso que interessa a esta pesquisa, mergulhar no conceito de experiência promulgado por John Dewey. Não pretendendo aqui esgotar o conceito de experiência, mas para esclarecer o que seria aprender na/pela experiência, segundo Dewey, é relevante trazer o conceito nas palavras do próprio autor:

\begin{abstract}
'Aprender da experiência' é fazer associações retrospectivas e prospectivas entre aquilo que fazemos às coisas e aquilo que em consequência essas coisas nos fazem gozar ou sofrer. Em tais condições a ação torna-se uma tentativa; experimentarse o mundo para saber como ele é. O que se sofre em consequência torna-se instrução - isto é, a descoberta das relações entre as coisas. (DEWEY, 1959, p. 153).
\end{abstract}

É a partir desses estudos, de como aprendemos a partir das experiências, que interessa a interlocução entre as Artes Visuais e a Educação. Assim, não se trata de realizar uma pesquisa para pensar a inserção das Artes Visuais na Educação, para que os futuros profissionais possam desenvolver projetos, tomando como princípio os conceitos das Artes Visuais. É preciso ir além, ou seja, "aprender da experiência" é se permitir uma vivência estético-artístico na área das Artes Visuais que 
possibilitará pensar o lugar e o espaço dessa área de conhecimento na formação dos futuros professores.

\section{Travessia 2: Relato de uma experiência em Artes Visuais}

O Ser é o que exige de nós criação para que dele tenhamos experiência.

Merleau-Ponty

No primeiro semestre de 2014, surge o convite para participar do Grupo de Estudos "Estúdio de Pintura Apotheke2". O Grupo Apotheke, nasce do desejo da Profa. Dra. Jociele Lampert de apreender as Artes Visuais no campo da Educação. A professora fundou o Grupo de Estudos Estúdio de Pintura Apotheke com o objetivo de abraçar as suas pesquisas e inserir seus orientandos no universo das Artes Visuais e da Arte/Educação com estudos sobre Arte/Educação por meio da pintura, bem como no universo da produção artística do Artista/Professor/Pesquisador.

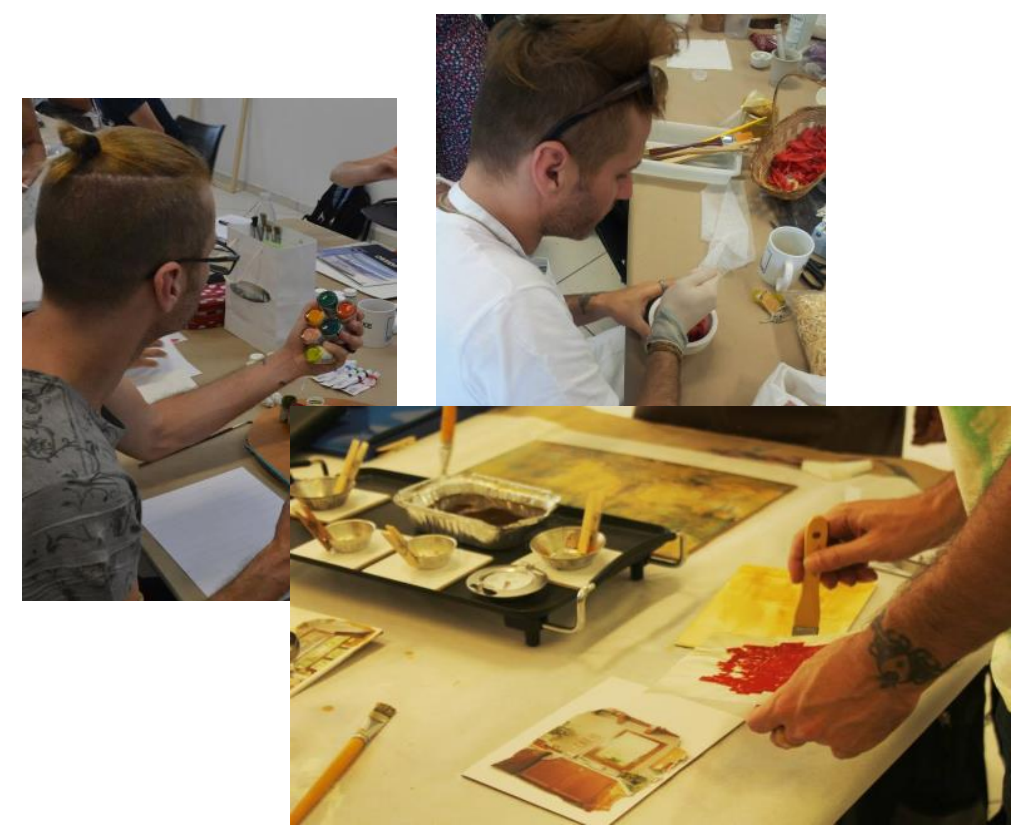

Figura 01 - Estudos de técnicas no Grupo de Estudos Apotheke. Fotografias do autor. Sem dimensão definida, 2014.

\footnotetext{
${ }^{2}$ A palavra tem origem grega no substantivo apotheke, que designava armazéns do porto de Atenas na Grécia Clássica. Também de origem germânica, remonta à palavra botica, boticário ou farmácia. A escolha por esta nomenclatura decorre da percepção da botica como lugar de laboratório, de um labor experimental. Isso se aproxima da proposta do grupo a ser constituído, tendo a pintura como eixo norteador para o processo artístico e considerando o campo ampliado e os possíveis desdobramentos para o pensamento plástico-pictórico. Fonte: Projeto de Pesquisa: "Arte Educação pela pintura: a produção artística do artista professor". http://www.revistas.udesc.br/index.php/APOTHEKE/article/view/9487/654
} 
O grupo apresenta dois eixos em sua metodologia: o eixo prático e o eixo teórico. É relevante salientar que o Grupo não acredita na dicotomização entre prática e teoria, e os eixos são criados para fins didáticos. Sendo assim, no eixo prático, é previsto que os participantes realizem e compartilhem seus trabalhos realizados em seus estúdios. Ainda assim, trabalhos coletivos são realizados semanalmente com técnicas e pesquisa em pintura. Nesse mesmo eixo estão previstas saídas de estudo e pesquisa de campo: pintura ao ar livre; visitação a ateliês de artistas e, por fim, a realização de mostras, seminários, oficinas e publicações.

No eixo teórico, os participantes realizam leituras e reflexões específicas sobre os temas trazidos pela Coordenadora. É neste eixo que os registros acerca dos processos pictóricos dos participantes são realizados, assim como os registros das ideias que emergem do estudo das técnicas. Por fim, este eixo é responsável pela organização das publicações do Grupo.

Venho de uma formação cujo currículo não possui nada parecido com o que tenho experimentado e descoberto nos encontros do Grupo de Estudos "Estúdio de Pintura Apotheke". Digo "experimentado" e "descoberto" porque o grupo mantém seus encontros semanais regulares, e os relatos que trarei aqui estão pautados em 31 encontros.

Como recebi a ideia de participar de um Grupo de Estudos pela pintura?

Tendo em vista a minha formação como pedagogo, que até o momento experimentava Artes Visuais, exclusivamente como apreciador, ou apenas leitor de teorias da Arte/Educação, percebi que o que me fazia estar presente no grupo era experimentar tantas técnicas que se encontravam longe de fazer parte de qualquer componente curricular de uma Graduação de Pedagogia. Tive experiências estéticas, estava e estou em constante estado de experimentação estético-artística. O que tanto vasculho nos livros - o que é experienciar Artes Visuais? Como propiciar essa experiência para educadores e educandos?

Vivo a resposta a essas perguntas toda semana. Contudo, clarificar essa experiência em palavras tem sido um exercício. A cada encontro, muitas experiências são encarnadas e novas perguntas se incorporam nas anteriores - é um eterno fluxo e refluxo de experimentações. Toda experiência vivenciada nos encontros do Grupo de 
Estudos "Estúdio de Pintura Apotheke" contribuiu significativamente para que meus registros, ou seja, meus cadernos - que antes de fazer parte do grupo eram apenas registros com palavras - fossem gradualmente se transformando em registros mais próximos a uma prática poética. Ainda exercito essa prática, ou melhor, aquela mais próxima às expressões estético-artísticas - formas de pensar com a imaginação, que é a dimensão entre o mundo interno e externo, esse lugar "entre" que enriquece o mundo real, provando a todo instante que a capacidade criadora quer dizer experiência, dotada de onirismo e imaginação (WINNICOTT, 1982; DEWEY, 2010).

As experiências estético-artísticas experienciadas no Grupo de Estudos "Estúdio de Pintura Apotheke" colocaram-me em contato, mais uma vez, com os conceitos da arte como experiência defendidos pelo filósofo John Dewey (2010), mais especificamente com o conceito de impulsão, anunciado pelo autor. Para Dewey (2010, p. 143), impulsão se diferencia de impulso, impulsão "designa um movimento de todo o organismo para fora e para adiante, e dela alguns impulsos especiais são auxiliares". Diante desse conceito, começo a observar como sou impulsionado pelas experiências do meu processo poético. A partir do momento em que começo a colocar as minhas indagações no espaço estético-poético, desdobram-se outros questionamentos, onde vou procurar as "respostas" no próprio universo das Artes Visuais: cadernos de artistas, exposições, e entrevistas com artistas. As indagações começam a circular na seguinte esfera:

- Por que foi importante fazer registros dos meus processos estético-artísticos?

- Como foi compreender a imaginação a partir dos meus exercícios estéticoartísticos?

- Como pensar um projeto de formação pautado na experiência artística?

Minhas convicções sobre aprender Artes Visuais estavam, a cada encontro, se transformando em indagações distantes de respostas, a priori. Foi então que meus cadernos-poiesis começaram a ganhar novos formatos, passando a existir como uma extensão do meu pensamento reflexivo-poético. Toda essa impulsão, que ganha forma/conteúdo nos meus cadernos-diários, na forma de mapas, registros rabiscados de meus pensamentos sobre Artes Visuais, Educação, Arte/Educação, origina um pensamento estético acerca de novas maneiras de pensar um projeto educativo em Artes visuais, onde este projeto esteja articulado à experiência e ao conteúdo específico do campo das Artes Visuais. John Dewey (2010) explica que essa experiência que não sabe para onde vai é resultado das nossas resistências e 
contenções de experiências prévias, ou seja, antecipações ansiosas pelos resultados e uma pseudossegurança gerada pelas respostas objetivas (DEWEY, 2010).

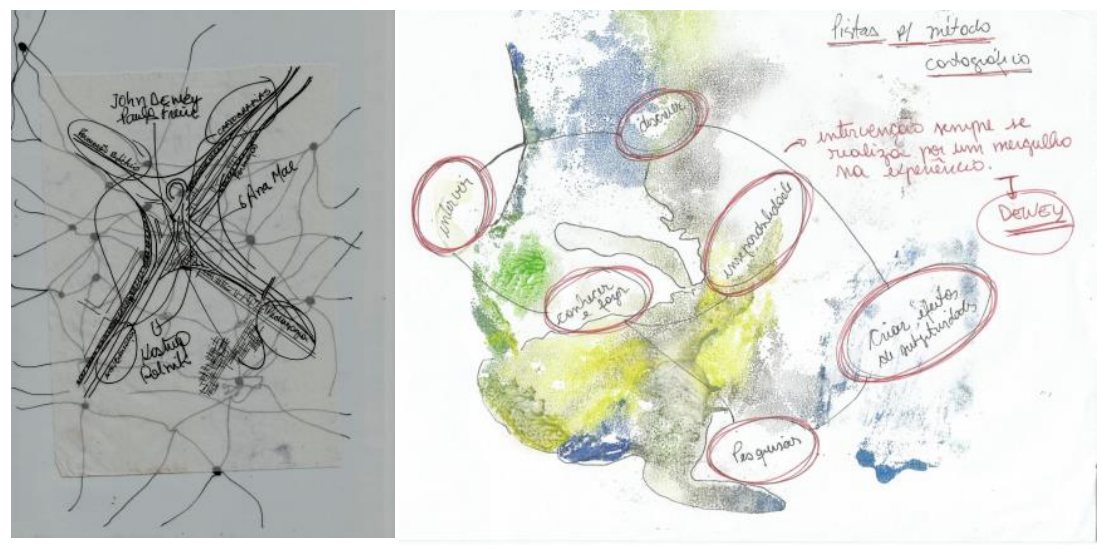

Figura 02 - fragmentos do diário de Fábio Wosniak. 2014/15. Acervo do autor.

Para que a junção entre o velho e o novo sejam recriações com potência criativa, o filósofo sugere que esse material antigo seja "ressuscitado" e encontre novas situações. Elas precisam ser asseguradas por ambientes potencializadores, onde as atividades não esbarrem em obstruções cegas, coisas retidas, ou em rotinas inertes. É necessário que o ambiente envolva e reforce as energias da pulsão original com discernimento em objetivos e métodos, que se revestem em experiências significativas (DEWEY, 2010). Almeida (2009, p. 23-24) tece esse pensamento de forma clara, quando nos diz que:

Trabalhar com a experiência requer abordagens não abstratas com foco no existir e fazer cotidianos, e que acolha sua subjetividade, ambiguidade e contraditoriedade. Alcançá-la requer interrogar fatos e certificar-se de que respondam com sua própria voz. (ALMEIDA, 2009, p. 23-24).

Com base nesse trabalho sobre a experiência, revendo a minha prática estética a cada encontro do grupo, fui direcionado a compreender sobre qual estética eu tentava falar, quando compreendi que a estética que experimentava é:

A estética que vem identificar-se com a lógica. Não mais apenas com a ética. Com a lógica também. Ela vem como essência formal de toda prática, é figura do real, é condição essencial da existência no plano das forças visíveis, é a forma, por excelência. (PEREIRA, 2013, p. 128). 
Porém, não satisfeito com esta definição, buscava outro conceito que contemplasse a estética mais inclinada ao campo da existência do que exclusivamente inserida no campo da lógica. Foi então, em uma segunda leitura deste mesmo livro, que pude observar que o autor partia de um ponto que se encontrava alinhado às minhas experimentações, ou seja, de um sujeito que se faz autor de si - era esse o meu exercício dentro do Grupo de Estudos "Estúdio de Pintura Apotheke" (PEREIRA, 2013).

Voltando ao conceito de estética postulado por Pereira (2013), o autor esclarece que uma

[...] estética da existência, a vida de autoria de si mesmo [...] quero, com isso, considerar a necessidade de o sujeito operar a partir da consideração de que sua singularidade resulta de uma auto-afirmação como fonte existencial, como uma "máquina autopoiética" [...] ou seja, é necessário compreender que os modos de produção de subjetividade são fabricações apropriáveis. $O$ fato de haver um modo hegemônico é, já, a evidência de que há outros modos possíveis. (PEREIRA, 2013, p. 118-119).

Procuro justamente esses outros modos possíveis quando me refiro a "outras maneiras" de aprender Artes Visuais. Quero dizer, dar voz e corpo para que esses outros modos possíveis surjam como pesquisa. Antes de entrar em contato com o conceito acima, acreditava que essas "outras maneiras" eram apenas pensar um ensino/aprendizagem que contemplasse técnicas em práticas estético-artísticas. Agora, vejo que é bem mais que isso. Outros modos possíveis, ou outras maneiras de pensar a aprendizagem em Artes Visuais, e a Arte/Educação, estão intimamente relacionados ao flexível-híbrido-fluido (ROLNIK, 2011).

Segundo Rolnik (2011), as Artes Visuais têm o poder de traçar e ressoar cartografias culturais contemporâneas, pois as experiências estéticas resultantes dessa contemporaneidade partem das inquietações dos sujeitos das experiências, que registram com as suas obras uma arte prêt-a-porter ou obras comprometidas com uma atitude político-poética (ROLNIK, 2010, p. 23). Obras prêt-a-porter, para a autora, são políticas de criação:

Extirpada[s] de sua vitalidade político-poética, a força de criação tende então a produzir cartografias a partir do mero consumo de ideias, imagens e gestos prêt-a-porter. A intenção é recompor rapidamente um território de fácil reconhecimento, na ilusão de silenciar as turbulências 
provocadas pela existência do outro. Produz-se assim uma subjetividade aeróbica portadora de uma flexibilidade acrítica, adequada ao tipo de mobilidade requisitada pelo capitalismo cognitivo. (ROLNIK, 2010, p. 20-21).

É evidente que uma política da criação dissociada destas produções prêt-a-porter mencionadas por Suely Rolnik (2010) investem em plasticidades políticas que consideram a fluidez híbrida contemporânea. São a partir das tensões das experiências contemporâneas que se "afirma (...) o poder poético da arte: dar corpo às mutações sensíveis do presente" (ROLNIK, 2010, p. 24).

Diante dessas duas maneiras de olhar para o universo do processo artístico resolvi investigar, e com base nessa percepção da fluidez-híbrido-fluido "mergulhei" no conceito de "outras maneiras de pensar" sobre como elaborar um roteiro de aprendizagem em Arte/Educação. Um projeto educativo em Artes Visuais, onde exista uma política de criação reflexiva, deve estar voltado a pensar em atitudes distantes daquelas que produzirão "subjetividades aeróbicas". A ideia que emerge dessas leituras e na elaboração de um projeto de aprendizagem em Artes Visuais, pretende:

\footnotetext{
Apreender o movimento que surge da tensão fecunda entre fluxo e representação: fluxo de intensidades escapando do plano de organização de territórios, desorientando suas cartografias, desestabilizando suas representações e, por sua vez, estancando o fluxo, canalizando as intensidades, dandoIhe sentido. (ROLNIK, 2011, p. 67).
}

Até chegar a essas linhas de pensamento, vivenciei durante o ano de 2014/15/16 diversas práticas artístico-estéticas no Estúdio de Pintura Apotheke. Somente mergulhado nessa processualidade pude experienciar um saber-fazer em Artes Visuais ancorado na experiência como fator determinante para uma política da criação significativa. A ideia era a de não promover o pensamento de que as Artes Visuais são exclusivamente um conjunto de técnicas específicas, mas também uma maneira de pensar acerca das coisas do mundo - e, principalmente, uma maneira de saber sobre a minha experiência poética articulada a minha prática docente.

\section{Travessia 3: Cartografias de uma experiência consumatória em Artes Visuais}

Essa forma de trabalhar, pela arte como experiência, com o conhecimento produzido em uma pesquisa em Artes Visuais permite traçar uma cartografia, onde o trabalho do pesquisador sempre se renova e desdobra-se em outros saberes. 
No caso específico deste estudo, abriu-se a possibilidade de pensar em uma atualização do conceito de experiência do filósofo John Dewey. Contudo, encontro em um "pedaço" do potente trabalho de Dewey, junto com escritos de Ana Mae Barbosa (2001), uma teoria que consiste em desvelar a experiência consumatória de um aprendiz em um Mestrado em Artes Visuais.

A palavra consumatória deriva do latim cõnsummãre. No dicionário etimológico da língua portuguesa, é encontrada junto ao conceito da palavra "consumar", que significa "terminar, completar, acabar" (CUNHA, 2010, p. 174). Porém, o significado do qual se origina a palavra não encontra ressonância na teoria de Dewey. Para o filósofo, "consumatória" em nada se aproxima de acabamento, término ou completude. Como já foi mencionado, consumação está mais relacionado a um nutrirse constantemente. Dewey chega a este conceito da palavra consumatória devido à importância revelada sobre sua argumentação de uma experiência pautada na qualidade estética, como explica Barbosa:

Para refutar a interpretação restrita de consumatório como conclusão de uma experiência, temos que pensar nas designações diferentes usadas por Dewey para falar da qualidade estética em uma experiência. Por exemplo, não podemos interpretar o significado de consumatório, expresso nos escritos de Dewey, sem relacionar a designação de consumatória com seu conceito de estética como uma qualidade difusa. Sendo consumatória, a estética é uma qualidade difusa que permeia a experiência como um todo, o que é completamente diferente do conceito de arte como ponto final de uma viagem através de várias disciplinas agrupadas em torno de um tema. (BARBOSA, 2001, p. 15556).

Por esse motivo, Dewey alerta que o estético e o artístico convergem, em vez de se dissociarem. Tanto para o espectador quanto para o artista, nenhum dos conceitos é projetado exclusivamente através do ato de criar para um, mas pelo de perceber para o outro. A obra de arte como um "ato mágico" - onde um cria da esfera etérea, e o outro apreende somente da emoção de ver - não é o projeto deweiano de apreensão estética.

Ambos artista e espectador ideal estão bem informados. O contexto afeta os dois, que traduzem de maneira singular a produção de cada um nas suas respectivas especificidades - de criar e de perceber. O que Dewey revela com esta afirmação é que uma obra tem que ser estética para ser artística, pois a obra é moldada para 
uma percepção. Para o autor, essa percepção deve ser prazerosa. O prazer a que Dewey se refere está intimamente ligado ao componente paixão, presente em todo ato de percepção. Para o filósofo, quando o organismo é tomado por sentimentos como a raiva e o ciúme, a experiência é inestética.

Porém, não é possível confundir este ato prazeroso do qual nos fala Dewey como um ideal romântico, utópico ou ingênuo de que a Arte só é Arte quando revela a paixão, ou confundida com o belo. Não é destes sentimentos que fala o autor. É importante ressaltar que Dewey esclarece, em sua obra, que todo equilíbrio da experiência estética possui elementos de equilíbrio e proporção e, para alcançar este potencial, que aparecerá na experiência estética, o organismo passa por uma "batalha" de sentimentos até o ato da escolha. Só assim a obra se torna controlada por um ato refinado, inteligente e adequado à situação (DEWEY, 2010). O desafio do artista com sua obra estético-artística, mesmo que ela cause um incômodo emocional, é levar a apreciação à indagações consumatórias, onde o perceptor encontre caminhos que o levem a refletir sobre o motivo de tal incômodo.

Sobre a produção artística, Dewey revela que "o verdadeiro trabalho do artista é construir uma experiência que seja coerente na percepção ao mesmo tempo que se mova com mudanças constantes em seu desenvolvimento" (DEWEY, 2010, p. 132). A Arte, nesta perspectiva da filosofia da experiência, é conhecimento. Dewey apresenta em sua filosofia da Arte como experiência que ela está saturada de significados. Na sua concepção teórica esses significados estão para além das estruturas elaboradas pela linguística, ou seja, para além do conceito de conhecimento que nos são apresentados pelas teorias cognitivas tradicionais (BARBOSA, 2001). Para Dewey, os significados devem ser absorvidos antes de serem conhecidos - eles precisam ser compreendidos antes que sejam conhecimentos. Segundo Barbosa (2001, p. 149),

[p]ara Dewey, a concretização do significado da experiência estética e artística é mais do que conhecimento se fizermos uma analogia com o que ele disse sobre a experiência de ver e manusear uma flor: "desfrutar o significado completo do cheiro, como o odor dessa bela coisa, não é conhecimento, porque é mais do que conhecimento".

O estético e o artístico abrem o desdobramento de possibilidades das relações entre o sujeito e o mundo, proporcionando reflexão e ação, ou seja, a construção de um conhecimento experiencial. Ela implica todo o organismo, colocando-o em 
movimento, em fluxos, e afastando-o da imobilidade. Propicia a investigação estético-artística e, enquanto uma prática do organismo vivo, torna-se contínua, não determinada por um conceito ou teoria simplista, mas configurada por uma potência de criação.

Esse fazer que a investigação artística tonifica aceita que a forma/obra é parte de um processo trânsito entre um antes que acontece sempre no agora e um depois que densifica a possibilidade de existência do antes. (NEUPARTH, 2011, p. 20).

Como explicitado na citação de Neuparth (2011), percebemos, como evidência Dewey, que a obra de Arte é um todo que abrange o universo em que vivemos. Essa intensidade estética do todo que a obra de arte apresenta é "mais do que conhecimento", ou seja, é a forma requintada que a inteligibilidade e a clareza de uma investigação que privilegia a experiência estético-artística apresenta à experiência. Nas palavras de Dewey, "a obra de arte atua aprofundando e elevando a uma clareza maior a sensação de um todo indefinido e abrangente que acompanha toda experiência normal" (DEWEY, 2010, p. 351).

O todo do qual Dewey nos fala é "a qualidade penetrante de uma experiência" (DEWEY, 2010, p. 350), são todas as coisas presentes no mundo que estão vinculadas à nossa consciência, pois a medida da nossa imaginação nesse todo movese à medida que nos movemos. Por este motivo, a experiência tem também um caráter místico, pois seu sentido, a sensação ilimitada que está diretamente ligada à experiência estética, funde-se na obra de Arte fazendo com que a sensação que temos ao apreciar uma obra de arte resulte em uma totalidade comemorativa, expectante, insinuante, premonitória e transgressora (DEWEY, 2010).

O meio e o fim em uma obra de arte aproximam-se, mesmo que no início da criação esteja instaurado o caos. Aos poucos, o movimento ordeiro da experiência encontra nos fluxos da consciência a primeira camada de entendimento dos movimentos resultantes dos efeitos estéticos, os veículos da composição da obra, um-a-um. Esses movimentos não são externos, são intrínsecos ao criador, são as áreas da nossa vida. Eles estão integrados, são os meios e o fim do processo da aprendizagem. Por isso, a técnica não é o processo artístico, mas um meio de chegar a ele.

A Arte "é uma variedade da experiência, e não uma entidade em si (...) a experiência é uma questão da interação do produto com o eu" (DEWEY, 2010, p. 558). O encontro 
da interação implica o movimento de todo o organismo envolvido no acontecimento da experiência estético-artística, e este percurso é o "acontecer da criação". Para que ele seja reconhecido e perpasse pela experiência estética, o que acontece antes da criação é um estado peculiar na apreciação do artista, que mais tarde é apresentado como uma ideia poética. Por sua vez, a ideia poética fará emergir as distinções - a singularidade que, por mais vagante e indefinida que seja, as partes definidas deste percurso apresentarão suas qualidades imediatamente experimentadas quando a percepção ganhar potência na consciência.

As partes e a qualidade que perpassam cada movimento é explicado por Dewey da seguinte maneira:

[...] a qualidade penetrante que perpassa todas as partes de uma obra de arte e as une em um todo individualizado só pode ser "intuída". Os diferentes elementos e as qualidades específicas de uma obra de arte mesclam-se e se fundem de um modo que as coisas físicas não conseguem imitar. Essa fusão é a presença sentida da mesma unidade qualitativa em todas elas. As "partes" são discriminadas, e não intuídas. Mas, sem qualidade intuída envolvente, as partes são externas umas às outras e mantêm uma relação mecânica (...) o organismo que é a obra de arte em nada difere de suas partes ou membros. Ele é essas partes como membros - o que novamente nos eleva à qualidade penetrante que se mantém a mesma ao ser diferenciada (...). (DEWEY, 2010, p. 348).

As partes e a qualidade não são exibições realistas, elas compõem um idioma singular que só acontece na obra. Em uma obra de arte, não existem "bordas" que a delimitam. A experiência penetrante do que acontece na obra de arte tem seu contexto indefinido, as coisas das quais resultam de uma apreciação são apenas pontos focais do instante. O "pano de fundo" apresentado pela obra de arte é seu caráter ilimitado.

O idioma singular é criado pela incansável busca do artista em descobrir sua poética, sua maneira singular de expressar suas impressões do mundo a partir do seu trabalho estético-artístico. Ao mesmo tempo, "toda arte é, de algum modo, um veículo dessa transmissão, enquanto seus produtos são uma parte nada insignificante da matéria saturada" (DEWEY, 2010, p. 552). Além disso, Dewey também afirma que em todo o trabalho do artista existe uma acelerada intenção de superação da sua técnica, de uma constante busca pelo novo. Isso seria o amadurecimento de cada processo 
criativo, onde a superação do banal e a esperança do novo a cada produção é apresentada através da obra, como se um idioma fosse sempre nascendo.

Paul Klee revela em seu diário:

De fato, começo a ver um caminho que poderá levar a um desenvolvimento do meu tipo de linha. Finalmente encontro uma saída para o beco sem saída do ornamento, em que me vi em 1907!

Refortalecido por meus estudos naturalistas, posso ousar adentrar uma vez mais o meu campo primordial da improvisação psíquica. Aqui, ligado a uma impressão natural apenas de forma totalmente indireta, posso ousar novamente dar forma ao que já levo na alma. Anotar vivências que podem se transformar em composições lineares até mesmo na noite mais escura. Aqui, há muito tempo existe uma nova possibilidade criativa, outrora interrompida pelo medo do isolamento. Desta forma, minha verdadeira personalidade ganhará expressão, e poderá se espraiar no campo da liberdade máxima. (KLEE, 1990, p. 266).

Nessa citação, é possível observar a busca do artista pelo seu "idioma" singular, bem como a superação da sua técnica, que Ihe confere uma liberdade máxima no seu processo criativo. Paul Klee encontra o fortalecimento da sua forma, presente na sua alma, após dedicar-se aos exercícios da pintura naturalista, que garantiu que o artista não tornasse a sua produção linear, onde as linhas limitavam as áreas de tonalidades e cor. O artista também encontrou nas obras de Van Gogh e Ensor o "apoio" para reconhecer a sua nova forma de criação.

Do ponto de vista do espectador que vivencia uma experiência estética, Jean Genet (1910-1986) revela acerca da obra de Giacometti (1901-1966) que:

Os rostos pintados por Giancometti parecem ter reunido tamanha vida que já não lhes resta nenhum segundo a viver, nenhum gesto a fazer, e (não que tenham acabado de morrer) conhecem enfim a morte, pois um excesso de vida ali está acumulado. Visto a vinte metros, cada retrato é uma pequena massa de vida, dura como um cascalho, cheia como um ovo, que poderia alimentar sem esforço cem outros retratos. (GENET, 2000, p. 47).

Observamos, tanto do ponto de vista do artista (Klee), quanto do ponto de vista do espectador (Genet), a presença do todo que a obra de Arte apresenta, bem como a experiência consumatória. Em seus estudos, Klee procura refletir sobre uma outra maneira de potencializar a sua poética. Do outro lado, Genet, através das 
observações das obras de Giacometti, traça toda uma reflexão sobre a existência da obra do artista e o quanto ela "desafia" questões existenciais como a morte e a vida, observadas de longe e de perto.

O questionamento que aparece é o da imanência do tempo, do espaço e da luz. Em contrapartida, Klee reflete sobre a busca da maioria dos seres humanos, a liberdade máxima, ou seja, o inatingível. A liberdade da qual nos fala Klee é impossível de ser atingida no mundo real. A produção poética é capaz de proporcionar essa sensação e até de revelar essa sensação a partir da composição do artista, mas como seres inseridos em uma sociedade, somos limitados pelas regras e convenções, pelo nosso imaginário - o que nunca nos tornará seres completamente livres, a não ser pela "falsa" sensação presente nas Artes.

A Arte, mais especificamente a pintura, coloca nosso olhar em questão, comunicando com estranheza sua existência secreta - como nas linhas de Klee e na descrição sobre os rostos de Giacometti revelados por Genet. A materialidade da pintura nos coloca diante do mundo percebido, que na maioria das vezes nos esconde o conhecimento sedimentado imposto pela Ciência. Ao recorrer à pintura somos situados diante do mundo vivido. As obras de arte são "meios pelos quais entramos, através da imaginação e das emoções que elas despertam, em outras formas de relacionamentos e participação, diferentes das nossas" (DEWEY, 2010, p. 561).

As pinturas exigem de nós uma interpretação nova e original a cada vez que as observamos por meio de todo o nosso organismo. Todo o nosso corpo é invocado pela pintura, traduzimos toda a nossa existência a partir da apreciação de uma obra de arte. A presença da obra de arte completa os nossos desejos, proporciona novas experiências, ressignifica nosso mundo interior e exterior.

Sob esse foco, a obra de arte e sua compreensão manifesta, em toda a sua totalidade e qualidade estética, é o que a distingue das outras formas de conhecimento. A obra de arte é mais do que o mistério do gosto ou da expressão da sensibilidade, a arte e o processo artístico buscam uma forma própria de integração do homem com o mundo. No conhecimento artístico, as coisas não são parcelarizadas - a experiência é globalizante, integradora, promotora de experienciações e experimentações que evoluem para experiências estéticas, quando o planejamento é minuciosamente articulado para tal acontecimento. A objetividade a ser alcançada nesse projeto de conhecimento a partir da arte como experiência atravessa a objetividade 
simplesmente pelo encerramento do que está sendo proposto a conhecer. O objetivo se funde com o subjetivo, onde o sujeito que conhece integra-se através do seu plano de conhecimento com o objeto, pois ele, que aprende sob essa perspectiva, é capaz de criar a ordem, ou a maneira com que vai aprender. Tendo em vista que ele surge integrado no seio do próprio objeto, ele não está observando o mundo de fora, estamos todos imersos no mesmo mundo e dentro dele. É assim que a arte nasce, desse encontro do eu em sua completude com o mundo.

\section{Continuar a travessia: não há palavra final}

Trazer a Arte para o centro da vida cotidiana, como requer Dewey, é acreditar que esse cotidiano possa ser poetizado. O lugar potencial para que essas transformações ocorram seria, sem dúvida, os espaços educativos. Manter um projeto educativo voltado às questões estético-artísticas propiciaria que os novos apreciadores de Artes fossem realmente apreciadores capazes de transformarem as experiências incipientes em experiências singulares/estéticas.

Talvez o equívoco das teorias da educação, que perderam de vista o poder da Arte como fonte de um conhecimento original e transformador, foi substituí-lo por outras áreas de conhecimento que privilegiem um saber técnico em detrimento do saber da cultura. Isso ressoa na pouca capacidade dos nossos estudantes de reconheceremse na sua cultura imaterial e no saber ancestral da hibridização cultural que fazemos parte, deixando-se manipular por uma cultura de massa hegemônica que anula todo saber cultural herdado por outros povos, considerados menos capazes de produzir conhecimento.

Educar, pautado na perspectiva da Arte como experiência, é deixar com que os estudantes experimentem suas potencialidades, sua existência, de forma consciente. A Filosofia da Arte como experiência consumatória é educativa e deve ocupar os espaços escolares. Falar de conhecimento e de alternativas para tornarem as pessoas mais inteligentes é tarefa de uma Educação comprometida com as novas gerações.

É neste encontro do pensar e do fazer que o Grupo de Estudos Estúdio de Pintura Apotheke vai sendo organizado e desdobrado para outras possíveis reflexões. 0 Grupo tenta encontrar um movimento de pensamento e prática ordeiro, porém, com aberturas a futuras apreciações sob outras perspectivas de olhares. Por ser uma consumação da experiência, as considerações nunca são finais, mas pontuam respostas àquele determinado momento, ancorando os saberes/fazeres de seus 
participantes a superarem os desafios propostos por um saber/fazer/sentir em/com

Artes Visuais.

\section{Referências}

ALMEIDA, Célia Maria de Castro. Ser artista, ser professor: razões e paixões do ofício. São Paulo: Editora UNESP, 2009.

BARBOSA, Ana Mae. John Dewey e o Ensino da Arte no Brasil. São Paulo: Cortez, 2001.

CUNHA, Antônio Geraldo da. Dicionário etimológico da língua portuguesa. Rio de Janeiro: Lexikon, 2010.

DEWEY, John. Arte como experiência. São Paulo: Martins Fontes, 2010.

Experiência e Educação. Petrópolis, R.J.: Vozes, 2011.

Democracia e Educação. São Paulo: Companhia Editora Nacional, 1959.

GENET, Jean. O ateliê de Giancometti. São Paulo: Cosac \& Naify, 2000.

KLEE, Paul. Diários. São Paulo: Martins Fontes, 1990.

NEUPARTH, Sophia. Arte Agora: pensamentos enraizados na experiência. São Paulo: Anablume, 2011.

PEREIRA, Marcos Villela. Estética da professoralidade: um estudo crítico sobre a formação do professor. Santa Maria: Ed. Da UFSM, 2013.

ROLNIK, Suely. Cartografia sentimental: transformações contemporâneas do desejo. Porto Alegre: Sulina, Editora da UFRGS, 2011.

WINNICOTT, D.W. A Criança e o seu mundo. R.J.: LTC, 1982.

i Doutorando em Artes Visuais na Linha de Pesquisa de Ensino das Artes Visuais sob a orientação da Profa.
Dra. Jociele Lampert- PPGAV/UDESC; Mestre em Artes Visuais na Linha de Pesquisa de Ensino das Artes
Visuais - PPGAV/UDESC; Pedagogo habilitação em S.I. e E. I /2006 e S.E./2012 FAED/UDESC; Psicanalista;
extensão em História, Sociedade e Cultura - PUC/SP e imaginação Infantil e Arte Educação? PUC/SP. Fábio
trabalhou como Coordenador; Assessor Pedagógico e Professor de Artes em instituições Públicas e
Particulares de SC e SP. Em São Paulo, Fábio trabalhou nos anos de 2006 - 2011 como Assessor da
Prefeitura do Município de São Paulo em Arte Educação, Brincadeiras e Teatro. Vice-Coordenador da Rede
de Educadores de Museus de Santa Catarina - REM/SC (Gestão 2013-2015), membro/ pesquisador do Revista Digital do LAV - Santa Maria - vol. 11, n. 1, p. 103 - 120 - jan./abr. 2018 ISSN 1983 - 7348 http://dx.doi.org/10.5902/1983734827867 
Grupo de Pesquisa Arte na Pedagogia - Coordenado pela Profa. Dra. Mirian Celeste Martins (Mackenzie/SP), membro/pesquisador do Grupo de Pesquisa Entre Paisagem (UDESC/CNPQ) e integrante do Grupo de Estudos Estúdio de Pintura Apotheke - ambos coordenados pela Profa. Dra. Jociele Lampert (UDESC). Participa como editor assistente no periódico online Revista Apotheke. atuando principalmente nos seguintes temas: Arte Educação, Arte e Pedagogia, Formação Docente em Artes Visuais.

Como citar esse artigo:

WOSNIAK, Fabio. Cartografias de uma experiência em Artes Visuais. Revista Digital

do LAV, Santa Maria: UFSM, v. 11, n. 1, p. 103-120, jan./abr. 2018.

Enviado em: 27 de junho de 2017

Aprovado em: 27 de novembro de 2017. 